\title{
Improvement of Subgrade Characteristics Using Waste Plastic Bottle
}

Damilola A. Ogundare*,1, Ayokunle O. Familusi ${ }^{1}$, Babatunde E. Adewumi ${ }^{1}$, and Joel O. Olusami ${ }^{1}$ ${ }^{1}$ Lecturer and Researcher, Department of Civil Engineering, Federal Polytechnic, Ede, Osun State, Nigeria

\section{Keywords}

Durability,

Subgrade,

Stabilizing,

Waste Plastic Bottle,

California Bearing Ratio,

Unconfined Compressive Strength.

\begin{abstract}
The need to improve the strength and durability of subgrade soil in recent times has become imperative using stabilizing materials that can be sourced locally at no/or very low cost in other to reach their design life span before a major repair is required. This necessitates the improvement that could be achieved by stabilizing subgrade soil along Ede-Abeere road in Ede, Osun State with the Waste Plastic Bottle (WPB). The soil samples were collected at $1 \mathrm{~m}$ depth at different portions along the road and stabilized with varying percentages of WPB. Laboratory tests conducted were sieve analysis, natural moisture content, specific gravity, Atterberg limit, compaction, California Bearing Ratio (CBR), and Unconfined Compressive Strength (UCS) Test. The CBR of the stabilized soil ranges from $1.28 \%$ to $12.20 \%$ with $2.5 \%$ WPB having the highest $C B R$ value of $12.20 \%$ meeting the recommended value for unsoaked $C B R$ of subgrade soils. However, the statistical model reliably adjudged that there is a significant relationship between the CBR values of subgrade soil-WPB mixture obtained. Thus, it is recommended that WPB at $2.5 \%$ can serve as a stabilizing material as it increases the CBR of the subgrade soil and as an effective method of disposing of WPB.
\end{abstract}

\section{Introduction}

Transportation plays a vital role in the development of the economy, industry, society, and culture of any country and to achieve development in those fields, a satisfactory mode of transport is indispensable. This can be achieved through a transportation system that is economically viable. Practically, it is not possible to have a good subgrade always while constructing road pavement and with the aim of reducing pavement thickness on the poor subgrade, new techniques of construction and soil stabilization have been continuously explored. In the construction of pavements, subgrade serves as the foundation for the pavement, and for this purpose, an appropriate value of $C B R$ is required in subgrade soil in order to ensure adequate strength to support the imposed traffic load [1] However, not all subgrades are able to meet up this criterion because some have a considerably low and thus inappropriate CBR values [1] In such cases, natural soils are being treated with different kinds of materials to improve their engineering properties [2]

Improvement in subgrade has always been an area of concern to the highway and geotechnical engineers. In the case of a highway, a weak subgrade results in a greater thickness of the pavement layer which increases the cost of pavement construction. The economy in a road network can be achieved through economical pavement design as poor subgrade necessitates a greater pavement thickness resulting in increased construction cost [2].

In geotechnical engineering, soils with properties that cannot be safely and economically used for the construction of civil engineering structures without adopting some stabilization measures are referred to as weak or problematic soils. There are many types of problematic soils that hinder urban development in large cities. These could be swelling/shrinkage clays, collapsible soils, quick sands, frozen soils, and peat. The consequences that may be attributed to the behavior of such problematic soils can result in considerable financial loss [3]

The improvement in the strength and durability of lateritic soil in recent times has become imperative, which has encouraged researchers to use stabilizing materials that can be sourced locally at a very low cost and these local materials can be categorized as either agricultural or industrial waste [4]. Soil stabilization is a regulated process to improve the soil by using additives in order to use it as subgrade, base, or sub-base courses and carry the expected traffic and pavement loads. It aims at improving soil strength, controlling dust, and increasing resistance to softening by water through bonding of the soil particles together thereby waterproofing the particles or a combination of the two [5]. [6] define soil stabilization as the process of chemical, mechanical, and biological means of improving soil properties, therefore, made the properties of soil more suitable for engineering purposes. According to the American Society for Testing and Materials (ASTM), the main purpose of soil stabilization includes increasing the strength of existing soil to enhance its load-bearing capacity, permeability improvement, and enhancement of soil resistance to the process of weathering and traffic usage among others [7]. The improvement of subgrade soil is indispensable due to the rising cost of maintenance of road and there is need for provision of good roads and to concentrate on improving properties of soils using cost-effective practices. Plastics which is one of the solid waste types are materials made from a wide range of polymers of high molecular which consists a huge range of synthetic organic. It's a very huge issue to the whole world as it degrades very slowly to earth. They have broad applications in time and space due to their durability, ease of production, low cost, and relatively light weight [8]. However, recent decades have witnessed a tremendous increase in plastic used in day today consumer applications which have resulted in the municipal solid waste, an ever growing fraction of plastic materials that were used for a short time and then discarded. More than 23,400,000 million tons of plastics entered the Nigerian technosphere between 1996 and 2014 with less than $12 \%$ of the resulting waste in the recycling stream and about $80 \%$ of plastic goes to landfills and dumpsites [9]. Other disposal options include open burning and landfill fires which have led to environmental challenges such as diminishing landfill space, marine and urban littering resulting in air pollution. Considering the risks this volume presents to global and local environments and human health and since they are easily available, cheaper, and durable, there is therefore a growing need to 
find alternative use of plastic waste to lengthen the usage time of the plastic material and thereby save the degrading environment [10].

As the conventional additives (cement, geotextile, lime) for improving subgrade soil through stabilization becomes more expensive due to the high cost of production and emission of greenhouse gases such as carbon-dioxide (responsible for global warming), sustainable development use of solid waste material (waste plastic bottle) which can serve as an alternative should be encouraged in order to improve the mechanical properties of soil with low bearing capacity thus saving the natural resources for future purpose. [11] studied the improvement in $\mathrm{CBR}$ values on expansive soil subgrades using plastic strips and conclude that the insertion of reinforcement within the expansive soil subgrade is found to be effective in controlling the swelling significantly and the percentage reduction in swell potential however depends on the number of reinforcing layers and the type of reinforcement used. [12] used by-product steel slag to improve the engineering properties of clay soils. Laboratory and field experimental programs were developed to investigate the effect of adding different percentages of steel slag on plasticity, swelling, compressibility, shear strength, compaction, and California bearing ratio (CBR) of the treated materials. The results of tests on the clay soil showed that as steel slag content increased, the soil dry density, plasticity, swelling potential, and cohesion intercept decreased and the angle of internal friction increased. Also, the CBR results of the tests showed an increase in the CBR value with the increase in slag content. [13] studied the effect of High-Density Polyethylene (HDPE) plastic waste on the Unconfined Compressive Strength of soil. In a proportion of 1.5, 3, 4.5, and $6 \%$ of the weight of dry soil, HDPE plastic (40 microns) was added. They concluded that the UCS of black cotton soil increased with the addition of plastic waste. When $4.5 \%$ plastic waste was mixed with soil, the strength obtained was $287.32 \mathrm{KN} / \mathrm{m}^{\wedge} 2$ which is maximum because for natural soil, it was $71.35 \mathrm{KN} / \mathrm{m}^{\wedge} 2$. [14] utilized waste bottle plastic strips and lime as a soil stabilizer in the construction of flexible pavements. An attempt was made to lime stabilization of black cotton $(\mathrm{BC})$ soil with various percentages $(0 \%, 2 \%$, $4 \%$, and $6 \%$ ) of waste plastic bottle strips and study the engineering properties of soils compaction (MDD and OMC) including CBR at different percentages of plastic strips. It was concluded that $\mathrm{CBR}$ percentage of black cotton soil goes on increasing up to $4 \%$ plastic content in the soil and there on it decreases with increase in plastic content. Hence, we can say that $4 \%$ plastic and $5 \%$ lime content is the optimum content of stabilizers used in the stabilization of the BC soil.

[15] investigated the geotechnical properties of lateritic soil stabilized with banana leaf ash. Preliminary soil tests (natural moisture content specific gravity, and Atterberg limit) and engineering tests (compaction, California Bearing Ratio, and Unconfined Compressive Strength) were also carried out on the lateritic soil at their natural states and at when the banana leave ash was added to the soil at varying proportions of 2, 4, 6, 8 and $10 \%$ by weight of soil. The result of the strength tests showed that the banana leave ash enhanced the strength of the lateritic soil. The unsoaked $C B R$ value of the soil at its natural state was $10.42 \%$ and it got to the optimum value of $28.10 \%$ by addition of $4 \%$ banana leave ash by weight of soil. [16] evaluated the effectiveness of ground granulated blast furnace slag (GGBS) in improving the properties of existing soil to meet specified engineering requirements. Experimental investigations were undertaken on the index properties (Consistency Limits proposed by Atterberg, Specific gravity and Hydrometer analysis), compaction characteristics (MDD and OMC), and strength characteristics (Swelling pressure, direct shear, and CBR). Tests were carried out on the natural soil and also on treated soil. GGBS is added ranging from $0 \%$ to $40 \%$ of the amount of dry weight of natural soil. Test results indicate that Atterberg limits generally decrease, whereas the specific gravity of stabilized soil increases with higher GGBS content. There was an increase in the MDD observed and the OMC values decrease with the increase in GGBS content and at $20 \%$, the optimum value for dry density is achieved. Also, the CBR values increase with increasing GGBS content. The laboratory results obtained illustrate that at $20 \%$ optimum GGBS content, stabilization of the poor black cotton soil with GGBS satisfactorily meets the general specifications for subgrade materials.
The Nigerian population growth rate from the year 2000 to 2017 is at the average of 2.37 [17] and this can be related directly to the rate of increase in Municipal Solid Waste (MSW) generally and by extension, Waste Plastic Bottle (WPB). In the year 2007, world plastic production was estimated to be 260 million metric tons per annum with thermoplastic resins alone contributing about $67 \%[18,19]$. This estimate increased to 348 million metric tons in 2107

\section{Materials and Method}

\subsection{Materials}

The subgrade soil sample (Figure I) used for this study was collected along Ede-Abeere road, Ede North Local Government, Ede in Osun State of latitude; $7^{\circ} 44^{\prime} 60^{\prime \prime} \mathrm{N}$ and longitude $4^{\circ} 26^{\prime} 60^{\prime \prime} \mathrm{E}$. The top soil was

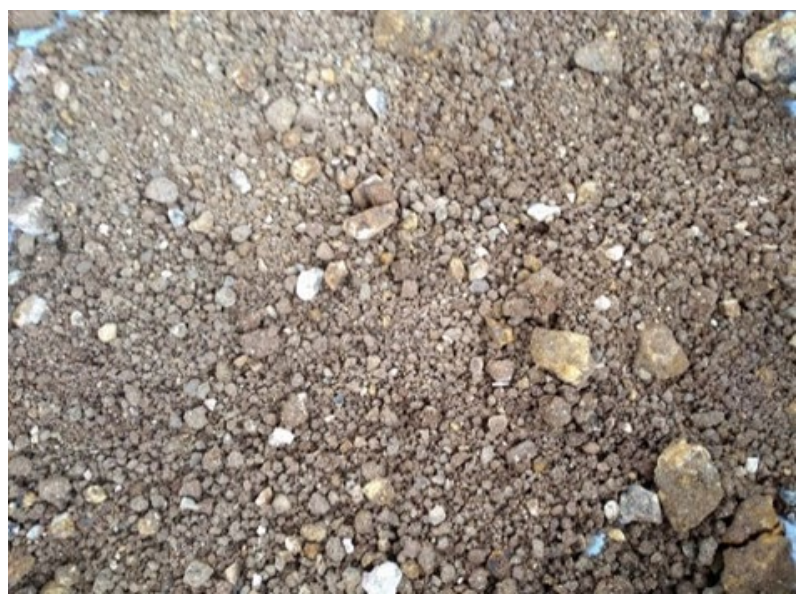

Figure 1. Soil Sample

\subsection{Methods}

The soil sample was collected in a polythene bag to avoid moisture loss during transportation. The sample was then sieved and preliminary tests like sieve analysis, natural moisture content, specific gravity, and Atterberg's limits test were carried out on the soil sample for easy identification and classification purposes.

Also, the stabilization process was carried out using WPB on the soil samples at $(0.5,1,1.5,2,2.5,3,3.5,4,4.5$, and $5 \%)$ by weight of the soil to determine the improvement of WPB on the soil sample. Engineering tests (Compaction, California bearing ratio (CBR) and Unconfined Compressive Strength) were performed on [20]. The authors further estimated that most of these materials are not biodegradable and are not part of the food chain thus, they end up in landfills and our water bodies where there is an absence or inefficient management of wastes, a situation which is more prevalent in developing countries like Nigeria. Though at many places, plastic wastes strips are being collected for recycling or reuse but unfortunately; the secondary markets for reclaimed plastic wastes strips have not developed and the best way to handle such wastes is to utilize them for engineering applications. Soil stabilization using waste plastic bottles can be a significant secondary market for plastic wastes materials and if found effective can be utilized as an innovative idea for enhancing subgrade soil which provides the base for the whole pavement structure and economical means to improve the engineering performance of the subgrade soil by replacing costly reinforcing materials like cement. Also, due to its non-biodegradability, it can help in solving the problem of disposal causing environmental hazards.

Removed to a depth of $1.0 \mathrm{~m}$ before the soil samples were taken. Also, the WPB (Figure II) used for this study were collected in the province of Ede, Osun State. These are plastic wastes of soft drinks and water 
bottles (Polyethylene Terephthalate, 'PET') and were cut suitably into uniform sizes of $15 \mathrm{~mm} \times 10 \mathrm{~mm}$.

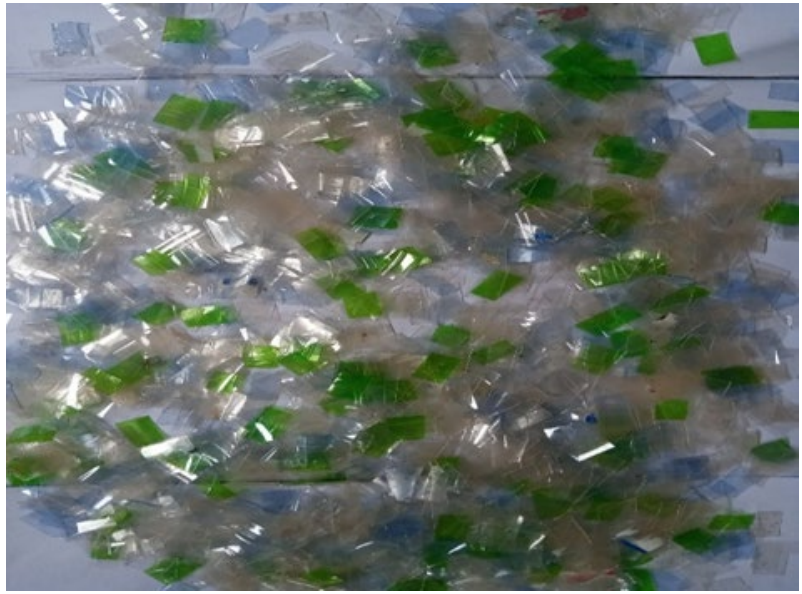

Figure 2. Waste Plastic Bottles of size $15 \mathrm{~mm} \times 10 \mathrm{~mm}$

The stabilized and unstabilized soil samples. The experiment on the soil sample was performed according to BS 1377 [21].

\section{Laboratory Tests}

\subsection{Mechanical Sieve Analysis}

This test was done to determine the grain size distribution of the soil sample by dry and wet sieving. Wet sieving was prepared by washing the soil sample through a $75 \mu \mathrm{m}$ micron sieve. The portion retained on the sieve was dried and sieved through a series of sieves. The procedures for the tests are detailed in BS 1377 [21].

\subsection{Moisture Content}

The moisture content of a soil is the ratio of the weight of water (W_w) present in the soil to the dry weight $\left(W_{-} d\right)$ of the solid soil particles expressed as a percentage. The mass of empty, clean, and dry moisture cans were weighed and recorded. The moist soil was placed in the moisture can and the mass was determined and recorded. The moisture can (containing the moist soil) was then placed in an oven (1050-1100C) to remove the moisture. The moisture cans were reweighed after 24 hours in an oven and the moisture content were determined (equation 1). The test was carried out in accordance with BS 1377 [21].

$w=\frac{W_{w}}{W_{d}} \times 100=\frac{W_{1}-W_{2}}{W_{2}-W_{3}} \times 100$

Where, W_1= weight of can and lid along with soil (g); W_2= weight of can and lid along with dry soil (g); W_3= empty weight of can and lid (g)

\subsection{Specific Gravity}

Specific gravity is the ratio of the weight in air of a given volume of a material at a standard temperature to the weight in air of an equal volume of distilled water at the same stated temperature. The sample was oven-dried at $1050 \mathrm{C}$ and was weighed in the pycnometer with and without water. The test was carried out in accordance with British Standard (BS) 1377 (1990) and was calculated as shown in "equation 2".
$G_{S}=\frac{W_{2}-W_{1}}{\left(W_{4}-W_{1}\right)-\left(W_{3}-W_{2}\right)}$

Where, W_1= weight of container (g); W_2= weight of the container and soil (g); W_3= weight of container, soil and water (g); W_4= weight of container and water (g)

\subsection{Atterberg Limit Test}

Atterberg limits tests were conducted on air-dried soils that had previously been passed through a sieve with $425 \mu \mathrm{m}$ aperture which include the determination of the liquid limit, plastic limit, and the plasticity index for the natural soil. The tests were conducted in accordance with BS 1377 [21].

\subsection{Compaction Test}

This test was carried out to evaluate the compaction characteristics of the soil sample and waste plastic bottle - modified soil. The Standard Proctor test was adopted and it involves compacting airdried soil sample into a cylindrical mold with $0 \%, 0.5 \%, 1 \%, 1.5 \%, 2 \%$, $2.5 \%, 3 \%, 3.5 \%, 4 \%, 4.5 \%$, and $5 \%$ uniform sized waste plastic bottle by weight of dry soil. The test procedure is described in BS 1377 [21].

\subsection{California Bearing Ratio (CBR) Test}

This test was used to examine the strength of the soil sample and waste plastic bottle - modified soil. The test involves compacting the unstabilized and the stabilized soil sample in the CBR mold at the optimum moisture content determined from the compaction test. The force on the plunger was read at every penetration of $0.25 \mathrm{~mm}$ dial gauge reading and the load at each penetration is recorded. The CBR is calculated using "equation 3 " and the test procedure is detailed in BS 1377 [21].

$\mathrm{CBR}=\frac{\text { Applied Force }}{\text { Standard value }} \times 100$

\subsection{Unconfined Compressive Strength (UCS) Test}

This test was done to determine the undrained shear strength of the soil sample and waste plastic bottle-modified soil. To perform UCS test, the sample is extruded from the sampling tube. A cylindrical sample of soil is trimmed such that the ends are reasonably smooth and the length-to-diameter ratio is on the order of two. The soil sample is placed in a loading frame on a metal plate; by turning a crank, (raising the level of the bottom plate). The top of the soil sample is restrained by the top plate, which is attached to a calibrated proving ring. As the bottom plate is raised, an axial load is applied to the sample. The crank is turned at a specified rate so that there is constant strain rate. The load is gradually increased to shear the sample, and readings are taken periodically of the force applied to the sample and the resulting deformation. The loading is continued until the soil develops an obvious shearing plane or the deformations become excessive. The measured data are used to determine the strength of the soil specimen and the stress-strain characteristics. Finally, the sample is oven dried to determine its water content and the maximum load per unit area is defined as the unconfined compressive strength, $q_{u}$. The test was carried out in accordance with ASTM D5102-09 [22] and the relevance UCS values are:

$q_{u}=\frac{P}{A}$

Where, $P=$ axial load at failure; $A=$ corrected area $A=$ $\frac{A_{o}}{1-\varepsilon}$

Where, $A_{o}=$ initial area of the specimen; $\varepsilon=$ axial strain 


\section{Results and Discussion}

Table 1 shows the results of the preliminary tests on the properties of subgrade soil samples without any stabilization agent.

Table 1. Preliminary Tests of the subgrade soil

\begin{tabular}{ll}
\hline $\begin{array}{l}\text { Summary of the Preliminary Tests } \\
\text { on Subgrade soil sample }\end{array}$ & Values \\
\hline AASHTO Classification & A $-2-4$ \\
Unified Soil Classification System & Well Graded Sand (SW) \\
Natural Moisture Content & $10.10 \%$ \\
Specific Gravity & 2.55 \\
Liquid Limit & $35.85 \%$ \\
Plastic Index & $4.96 \%$ \\
Shrinkage Limit & $9.97 \%$ \\
\hline
\end{tabular}

\subsection{Mechanical Sieve Analysis}

According to both the American Association of State Highway and Transportation Officials (AASHTO) and the Unified Soil Classification System (USCS), the soils are classified as A - 2-4 and well-graded sand (SW) respectively adjudging the soil as excellent to good material based on [23].

\subsection{Moisture Content}

The natural moisture content for the soil sample was $10.10 \%$ and according to [24] which shows the classification for moisture content for different soil types and indicates that natural moisture content in soil may range from below $5 \%$ to $50 \%$ in gravel and sand. The result of the samples shows that the values fall into the category of gravel and sand.

\subsection{Specific Gravity}

The specific gravity for the studied soil sample was 2.55 and according to [25], a good lateritic material should have specific gravity ranging from $2.5-2.75$. Based on this fact, the soil sample is considered to be acceptably high which may be attributed to the high mineral composition of the samples.

\subsection{Atterberg Limit Tests}

The results of Atterberg limit tests consisting; Liquid Limit (LL), Plastic Limit (PL), and Plasticity Index (PI) were 35.85\%, 30.89\%, and 4.96\% respectively; while the shrinkage limit was found to be $9.97 \%$. The liquid limit of the soil sample is within $35-50 \%$ which indicates medium plasticity while the plasticity index is below $12 \%$. They fall within the acceptable requirements for soil samples that can be used as subgrade or fill during construction of a highway in Nigeria according to [25].

\subsection{Compaction Test}

This test is used to establish a dry density/moisture content relationship of soil under a controlled condition which can form a standard for comparison with field specifications. It was observed that with an increase in WPB contents, the optimum moisture content decreased from $23.7 \%$ to $13.7 \%$ while the maximum dry density increased from $1920 \mathrm{~kg} / \mathrm{m}^{\wedge} 3$ to $2380 \mathrm{~kg} / \mathrm{m}^{\wedge} 3$ (Figures 3 and 4) when comparing the values at $0 \%$ and $3.5 \%$ WPB contents. These improvements in the natural and mechanical characteristics of soil stabilized with plastic strips is in line with the one observed by [26].

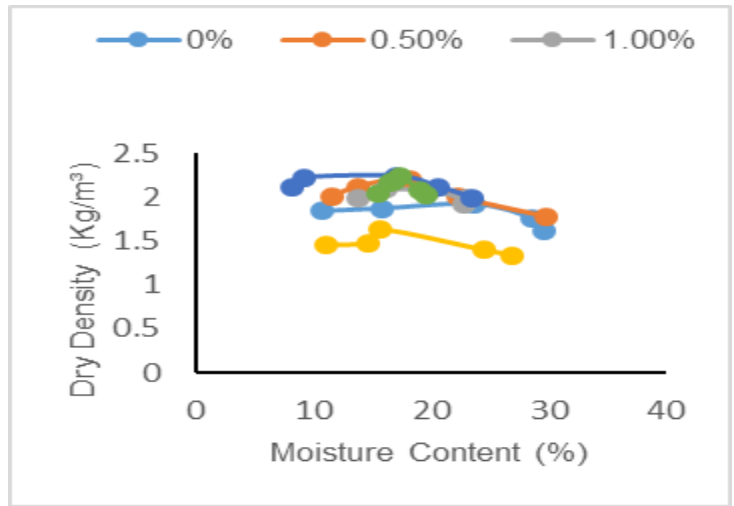

Figure 3: Effect of WPB on Compaction characteristics of subgrade soil

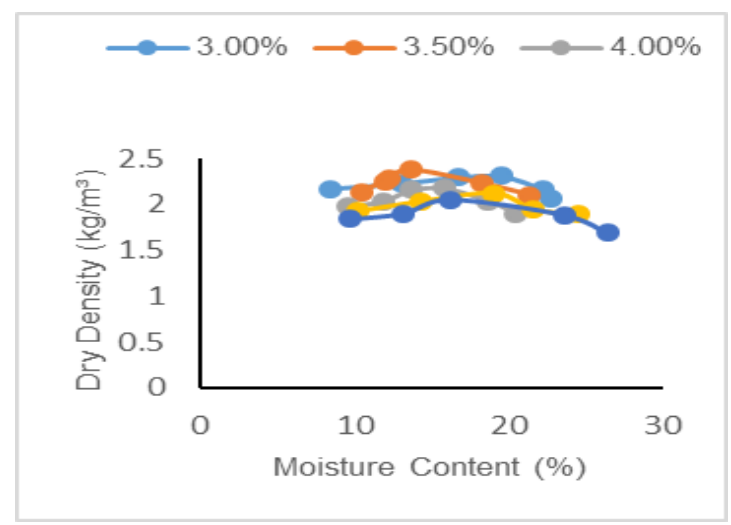

Figure 4: Effect of WPB on Compaction characteristics of subgrade soil

\subsection{California Bearing Ratio (CBR)}

The CBR is a semi-empirical test that is often employed in the estimation of the bearing capacity of subgrade, sub-base, and base materials [27, 28]. Figure 5 shows the graph of the CBR result with the unsoaked CBR value for the soil samples ranging from $1.28 \%-12.20 \%$. Federal Ministry of Works and Housing (1997) recommended unsoaked CBR for subgrade soils not less than $10 \%$. The result shows that the soil samples at $2 \%, 2.5 \%$, and $3 \%$ WPB $(10.12 \%, 12.20 \%$, and $10.70 \%$ ) have higher CBR values than the unstabilized ( $0 \%$ ) soil sample with $2.20 \%$ affirming that the former would be a suitable admixture for subgrade soil, especially at $2.5 \%$ WPB with the highest CBR value (12.20\%).

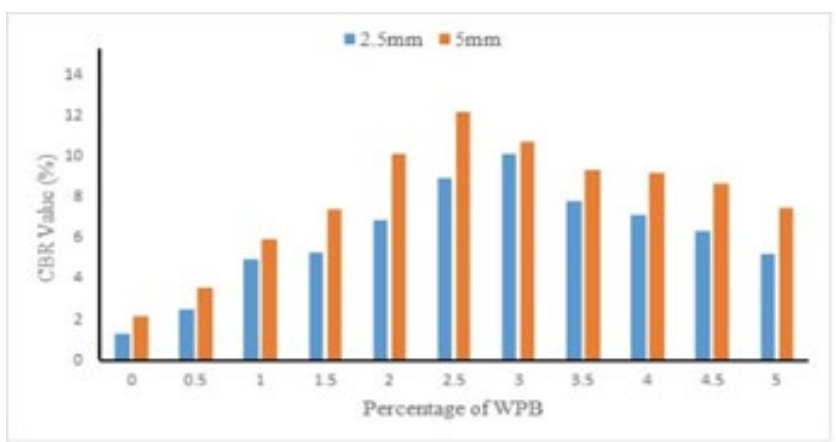

Figure 5: $C B R$ values at $2.5 \mathrm{~mm}$ and $5 \mathrm{~mm}$ penetration of $0 \%$ to $5 \%$ WPB 


\subsection{Unconfined Compressive Strength (UCS)}

The Unconfined Compressive Strength was used to determine the unconfined compressive strength, which is then used to calculate the unconsolidated undrained shear strength of the soil sample under unconfined conditions.

The Unconfined Compressive Strength of the soil samples at $0 \%, 2.5 \%$, $4 \%$, and $5 \%$ WPB were determined and their corresponding values were $177.2 \mathrm{kPa}, 153.6 \mathrm{kPa}, 162.7 \mathrm{kPa}$, and $174.7 \mathrm{kPa}$ respectively However, the Unconfined Compressive Strength of the unstabilized soil sample exhibits higher strength though, there was a gradual improvement in strength of the soil sample at $4 \%$ and $5 \%$ application of WPB. This reduction may be caused due to the non-pozzolanic reaction of the WPB-modified soil which helps in forming cementitious structure of the materials and action of WPB as a cushion in the soil and not providing enough water molecules to hold the soil particles together.

\subsection{Statistical Analysis (Analysis of Variance)}

To further validate the adequacy of the laboratory tests, analysis of variance (ANOVA) was used to ascertain whether or not the WPB content has any effect on the subgrade soil specimen. This analysis was conducted with the null hypothesis, which is the subgrade soilWPB mixture has no effect on the CBR, while the alternate hypothesis is that the subgrade soil-WPB mixture has an effect on the CBR. The result of the ANOVA test is summarized in Table 2.

Table 2. ANOVA Result

\begin{tabular}{lcclll}
\hline & $\begin{array}{l}\text { Sum of } \\
\text { Squares }\end{array}$ & $\mathrm{df}$ & $\begin{array}{l}\text { Mean } \\
\text { Square }\end{array}$ & $\mathrm{F}$ & $\begin{array}{l}\mathrm{P}- \\
\text { Value }\end{array}$ \\
\hline $\begin{array}{l}\text { Between } \\
\text { Groups }\end{array}$ & 125.058 & 10 & 12.506 & 3.634 & 0.023 \\
$\begin{array}{l}\text { Within } \\
\text { Groups }\end{array}$ & 37.859 & 11 & 3.442 & & \\
Total & 162.917 & 21 & & & \\
& & & & & \\
\hline
\end{tabular}

$\mathrm{df}=$ degrees of freedom; $\mathrm{F}=\mathrm{F}$ statistic

However, since the P-value is 0.023 , which is significantly lower than the significance value of 0.05 , the null hypothesis is rejected. In other words, WPB has a significant effect on the tested subgrade soil.

\section{Conclusion}

This study reveals that the subgrade soil belonged to subgroup A - 2 - 4 generating a rating for the subgrade soil as excellent to good material and well-graded sand (SW) based on AASHTO and USCS respectively. The results of the Atterberg limit test shows that the soil sample has a liquid limit of $35.85 \%$ and plastic index of $4.96 \%$ which falls within the acceptable requirements for soil sample that can be used as subgrade or fill during the construction of a road in Nigeria. However, the failure of the road may not be due to the infiltration of water into the subgrade layer. The stabilized soil at $3.5 \%$ WPB has the highest MDD (2380 kg/m^3) and lowest OMC (13.38\%) which implies a low affinity to absorb more water and swell on drying. The CBR value for the stabilized soil sample at $2.5 \%$ (12.20\%) attains the highest value of $\mathrm{CBR}$ than the unstabilized soil sample (2.20\%) affirming that the former is hereby recommended as a suitable admixture for subgrade soil as it meets the required standard set by Federal Ministry of Works and Housing (1997). Application of WPB gradually increases the Unconfined Compressive Strength of the soil sample at $4 \%(162.7 \mathrm{kPa})$ and $5 \%(177.2 \mathrm{kPa})$. However, further application of WPB may tend to improve the soil, as the strength increases with increase in percentage of admixture. Statistical model analysis proves further that there is a significant relationship between the subgrade soil-WPB mixture.

\section{Acknowledgements}

The authors are indeed grateful to Technical Staff at Civil Engineering Department and Civil Engineering Students, Federal Polytechnic Ede, Nigeria for their assistance during the laboratory works.

\section{Declaration of Conflict of Interests}

The authors declare that there is no conflict of interest. They have not known competing financial interest or personal relationships that could have appeared to influence the work reported in this paper.

\section{References}

[1.] Ogundare, D. A., Adebara, S. A., Familusi, A. O. \& Adewumi, B. E. Stabilization of Subgrade using Geosynthetics(Case StudyGeotextile) under soaked condition. International Journal of Engineering, Annals of Faculty Engineering, Tome XVI, 2018. 4, pp. 157-162.

[2.] Hossain, T., Ahmid, U. \& Slavaya, J. Waste Plastic on the Strength Characteristics of the Subgrade Soil. Proceedings of $2^{\text {nd }}$ International Research and Engineering Conference, 2015. 3(2), pp. 34-89.

[3.] Bell, F. G. \& Culshaw, M. G. Problem soils: A Review from a British Perspective, Proceeding of Problematic Soils Conference, Nottingham, Trent University, U.K. 2001. pp. 1-3.

[4.] Ogunribido, T. H. T. Potentials of Sugar Cane Straw Ash for Lateritic Soil Stabilization in Road Construction. International Journal of Science Emerging Technology, 2011. 3(5).

[5.] Sherwood, P. T. Soil Stabilization with Cement and Lime: A State of the Art Review, Department of Transport, Transport Research Laboratory, 1993. United Kingdom.

[6.] Oyediran, A. I. \& Kalejaye, M. Effect of Increasing Cement Content on Strength and Compaction Parameters of Some Lateritic Soil from Southwestern Nigeria, Electric Journal of Geotechnical Engineering, 2011. 16, pp. 1501-1514.

[7.] ASTM. Standards on Soil Stabilization with Admixtures, $2^{\text {nd }}$ edition: 2014. pp. 126.

[8.] Green Paper. Green paper on a European Strategy on Plastic Waste in the Environment. Brussels, European Commission, 2013. Available from: http://cor.europa.eu/en/activities/stakeholders/Documents/com m_123_2013_en.pdf

[9.] The Nigerian Plastics, Printing and Packaging Sector. Heidelberg, 2018. Germany. Available from http://www.pppnigeria.com/nigeria-plastic-print-package.html

[10.] Kalliyat, J. V., Joy, J. T., Paul, J. M. \& Vadakkel, A. M. Soil Stabilization using Plastic Fibres, International Journal of Sciences Technology and Engineering, 2016. 2(12), pp. 484-487.

[11.] Choudhary, A. K., Jha, J. N., \& Gill, K. S. Improvement in CBR Values of Expansive Soil Subgrades using Geosynthetics. Proceedings of Indian Geotechnical Conference, Guru Nanak Development Engineering College, Ludhiana 2011.

[12.] Shalabi, F. I., Asi, I. M. \& Qasrawi, H. Y. Effect of by-product Steel Slag on the Engineering properties of clay soils, Journal of King 
Saud University-Engineering Sciences, 2016. http://dx.doi.org/10.1016/j.jksues.2016.07.004.

[13.] Malhotra, A., Ghasemian, H., Kulkarni, D. R. \& Patil, N. R. Effect of HDPE Plastic on the Unconfined Compressive Strength of Black Cotton Soil, International Journal of Innovative Research in Science, Engineering and Technology, 2014. 3(1), pp. 8382-8389.

[14.] Reddy, N. H., Manjusha, P. \& Kulayappa, T. Utilization of Waste Bottle Plastic Strips and Lime as a Soil Stabilizer in Construction of Flexible Pavements, International Research Journal of Engineering and Technology, 2017. 4(4), pp. 1046-1051.

[15.] Nnochiri, E. S. \& Aderinlewo, O. O. Geotechnical Properties of Lateritic Soil Stabilized with Banana Leaves Ash, FUOYE Journal of Engineering and Technology, 2016. 1(1), pp. 116-119.

[16.] Mohammadia, M., Mallikarjuna, H. M. \& Hussain, A. Stabilization of Clay Subgrade Soils for Pavements Using Ground Granulated Blast Furnace Slag, International Journal of Engineering Development and Research, 2017. 5(4), pp. 764-773.

[17.] Indexmundi. Population Growth Rate of Nigeria. 2019. Retrieved from https://www.indexmundi.com/g/g.aspx?c=ni\&v=24.

[18.] Hopewell, J., Dvorak R. \& Kosior, E. Plastics Recycling: Challenges and Opportunities, Philosophical Transactions of the Royal Society Biological Sciences, 2009. 364, pp. 2115-2126.

[19.] Geyer, R., Jambeck, J. R. \& Law, K. L. Production, Use and Fate of all Plastics ever made, American Association for the Advancement of Science, 2017. 3(7), pp. 1-5.

[20.] Plastics-the Facts. An analysis of European Plastics Production, Demand and Waste Data. 2018.Retrieved from http://www.plasticseurope.org/application/files/6315/4510/9658 /Plastics_the_facts_2018_AF_web.pdf.

[21.] British Standard 1377. Methods of Test for Soils for Civi Engineering Purposes, British Standard Institution, 1990, London.

[22.] ASTM. Standard test method for Unconfined Compressive Strength of Compacted Soil - Lime Mixtures. D5102-09, West Conshohocken, PA. 2009b.

[23.] AASHTO. Standard Specification for Transportation Materials and Methods of Sampling and Testing, $14^{\text {th }}$ Edition, American Association of State Highway and Transportation Officials: 1986, Washington, D.C

[24.] Emesiobi, F. C. Testing and Quality control of Materials in Civil and Highway Engineering. ISBN 078-2009-36-16, 2000. pp. 5-7.

[25.] Federal Ministry of Works and Housing. General Specifications for Roads and Bridges. Government of the Federal Republic of Nigeria, Abuja, Nigeria, 1997. pp. 8-20.

[26.] Pandit, V. M., Dikkar, H. S., Patil, J. K., Rajput, K. G., Chavan, P. S \& Deore, Y. S. Effect of Plastic Strips on Compaction Characteristics of Soil, International Journal of Modern Trends in Engineering and Research, 2016. 3(4), pp. 1-6.

[27.] Simon, O. R., Richard, C. \& Banks, J. T. Particulates of Plastic in Soil Proposition, Journal Institution of Engineers, 1973. 84, pp. 257-262.

[28.] Gidigasu, M. D. Geotechnical Evaluation of Residual Gravels in Pavement Construction, Engineering Geology, 1980. 15(3), pp. 173-194.

\section{How to Cite This Article}

Ogundare, D.A., Familusi, A.O., Adewumi, B.E., and Olusamiv, J.O., Improvement of Subgrade Characteristics Using Waste Plastic Bottle, Civil Engineering Beyond Limits, 4(2021),1-7. https://doi.org/10.36937/cebel.2021.004.001 